\title{
Microstructure Evolution of Semisolid Mg-2Zn-0.5Y Alloy during Isothermal Heat Treatment
}

\author{
Liu Wei, $\quad$ Yang Doudou, Quan Gaofeng, Zhang Yingbo, Yao Dandan
}

Southwest Jiaotong University, Chengdu 610031, China

\begin{abstract}
Microstructure evolution of extruded $\mathrm{Mg}-2 \mathrm{Zn}-0.5 \mathrm{Y}$ (at\%) alloy in semisolid isothermal heat treatment process was investigated. The results show that in the alloy there are $\alpha-\mathrm{Mg}, \mathrm{Mg} 3-\mathrm{Zn} 6-\mathrm{Y} 1$ (I-Phase) and Mg3-Zn3-Y2 (W-phase), and the average grain size of $\alpha-\mathrm{Mg}$ is $7 \mu \mathrm{m}$. During the isothermal heat treatment at $793 \mathrm{~K}$, the grains continue growing and no liquid phase appears until isothermal holding time reaches $4.0 \mathrm{~min}$. With isothermal temperature rising and holding time increasing, solid $\alpha$-Mg grains in the alloy gradually grow and are separated by liquid phases. Meanwhile, the liquid phase locating both at the grain boundaries and in the grain interior significantly increases. It is also found that at higher solid fractions, particle coarsening mechanism and solid particle remelting mechanism both play major roles. While at lower solid fractions, Ostwald ripening is the major mechanism and coalescence of adjacent particles could be still observed.
\end{abstract}

Key words: Mg-Zn-Y alloy; semisolid; isothermal heat treatment; microstructure

Magnesium alloys are the lightest structural materials, and they are attractive for many applications such as automobile, aerospace and railway rolling stocks. In recent years, semisolid processes have become popular for industrial and commercial production because of their excellent advantages such as low temperature, low forming force, good quality of parts and so forth, over conventional casting and deforming processes ${ }^{[1-4]}$. Semisolid processes are divided into two categories, rheoforming and thixoforming. The main difference between rheoforming and thixoforming is that, semisolid slurry used in rheoforming is partially solidified from the liquid state, while that in thixoforming is partially remelt from the solid state. For both rheoforming and thixoforming, the key requirement is the thixotropic slurry with non-dendritic primary particles uniformly distributed in the liquid matrix. It is well accepted that, the finer and rounder the primary particles are, the better the rheology of semisolid slurry and the resulted mechanical properties will be ${ }^{[5]}$.

Thixoforming involves the reheating of feedstock materials into semisolid $\operatorname{state}^{[6]}$. In order to get non-dendritic microstructure via reheating, feedstock materials are always prepared by some special techniques, such as a strain induced melt activated (SIMA) technique and spray casting. SIMA technique introduces significant commercial advantages of simplicity and low cost. Generally, SIMA process consists of three discrete steps: casting of the alloy to achieve a typical dendritic structure, a predeformation to make the particle smaller and to store an internal energy and partial remelting of the alloy at semisolid temperatures ${ }^{[7]}$.

In recent years, magnesium alloys studied and used in semisolid processes are limited to commercial $\mathrm{Mg}$-Al alloys such as AZ91and AZ80 ${ }^{[8-10]}$. The application is then restricted by their inherent deficiencies ${ }^{[11]}$. Rare earth metals (RE) have been demonstrated the most effective elements to improve the mechanical property of magnesium alloys, especially at elevated temperature ${ }^{[12-15]}$. Recently, several works have focused on the SIMA route of $\mathrm{Mg}-\mathrm{Zn}-\mathrm{Y}$ alloys because of wide semisolid range and fine primary particles.

Received date: August 14, 2015

Foundation item: the Central University Basic Scientific Research Program (SWJTU11ZT30, SWJTU11CX050); the Key Program of State Key Laboratory of Track Power (2012A0101)

Corresponding author: Quan Gaofeng, Ph. D., Professor, College of Material Science and Engineering, Southwest Jiaotong University, Chengdu 610031, P. R. China, Tel: 0086-28-87634673, E-mail: quangf@gmail.com 
The aim of the present paper is to investigate the microstructure evolution of extruded $\mathrm{Mg}-2 \mathrm{Zn}-0.5 \mathrm{Y}$ alloy after semisolid isothermal heat treatment in different stages. What's more, the coarsening kinetics of Mg-2Zn-0.5Y alloy in semisolid state is also studied.

\section{Experiment}

Mg-2Zn-0.5Y (at\%) alloy used in the present study was prepared with commercial high purity magnesium (99.99\%), commercial high purity zinc (99.99\%) and $\mathrm{Mg}-25 \mathrm{wt} \% \mathrm{Y}$ master alloys by melting in an electric resistance furnace under the mixed atmosphere of $\mathrm{CO}_{2}$ and $\mathrm{SF}_{6}$. The melt was cast into a $523 \mathrm{~K}$ preheated cylindrical permanent mold, and then a $\Phi 95$ $\mathrm{mm}$ ingot was acquired. The ingot was extruded to a $\Phi 10 \mathrm{~mm}$ round rod after a homogenization treatment at $653 \mathrm{~K}$ for $16 \mathrm{~h}$. The extrusion speed was $0.05 \mathrm{~m} / \mathrm{s}$, and the extrusion ratio was 81:1. $\Phi 10 \mathrm{~mm} \times 15 \mathrm{~mm}$ samples were cut from the extruded round rod for isothermal heat treatment. When the furnace was heated to different temperatures between 793 and $853 \mathrm{~K}$, the samples were put into the furnace and held for various times between 2 and $30 \mathrm{~min}$. After the isothermal heat treatment, the samples were taken out and quenched in cold water immediately.

The samples were prepared with standard metallographic procedures. Phase composition was characterized by Max 2500 X-ray diffraction (XRD). The microstructure and phase distribution were characterized by Zeiss Axio Lab A1 optical microscopy (OM) and JSM-6490LV scanning electron microscopy (SEM). The observed samples for OM and SEM investigations were ground, polished and etched by nital $4 \%$ solution and the mixture of $6 \mathrm{~g}$ picric acid, $10 \mathrm{~mL}$ distilled water, $5 \mathrm{~mL}$ acetic acid and $100 \mathrm{~mL}$ alcoholic solution. Quantitative analysis was carried out by Micro-image Analysis \& Process. Average particle size and the fraction of liquid were measured. The chemical compositions of phases were determined with GENESIS 2000 XMS energy dispersive spectrometer (EDS).

\section{Results and Discussion}

\subsection{Microstructure of extruded Mg-2Zn-0.5Y alloy}

The XRD pattern of the extruded $\mathrm{Mg}-2 \mathrm{Zn}-0.5 \mathrm{Y}$ alloy is shown in Fig.1. The XRD peaks evidently indicate that the alloy consists of $\alpha$-Mg, Mg3-Zn6-Y1 (I-Phase) and Mg3-Zn3-Y2 (W-phase).

Fig.2 shows the microstructure of the extruded Mg-2Zn- $0.5 \mathrm{Y}$ alloy observed by OM. As seen from Fig.2, the microstructure of the alloy consists of fine and equiaxed $\alpha-\mathrm{Mg}$ and dispersed second phase (I-Phase and W-Phase). The average grain size of primary $\alpha-\mathrm{Mg}$ is about $7 \mu \mathrm{m}$.

\subsection{Microstructure evolution of Mg-2Zn-0.5Y alloy after isothermal heat treatment (before liquid phase appearing)}

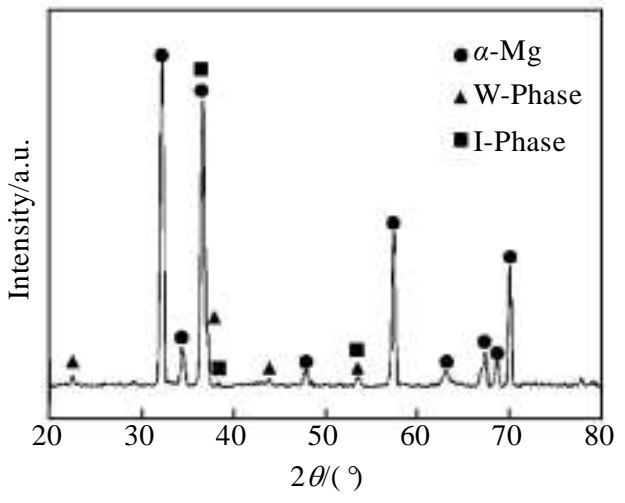

Fig.1 XRD pattern of the extruded Mg-2Zn-0.5Y alloy

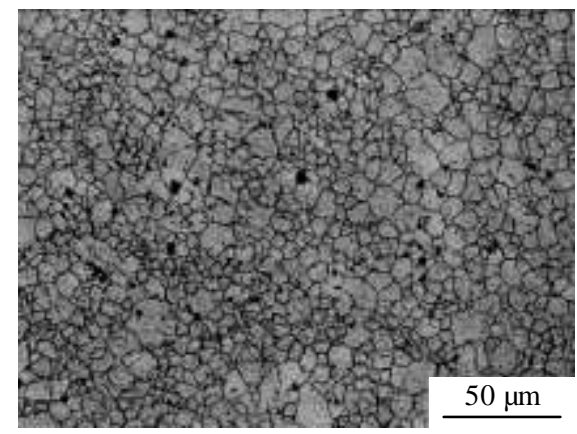

Fig.2 Microstructure of the extruded Mg-2Zn- $0.5 \mathrm{Y}$ alloy

Fig.3 shows the microstructure evolution of the Mg-2Zn-0.5Y alloy after isothermal heat treatment at $793 \mathrm{~K}$ for $2.0,2.5,3.0,3.5$ and $4.0 \mathrm{~min}$. The microstructure and grain size of the $\mathrm{Mg}-2 \mathrm{Zn}-0.5 \mathrm{Y}$ alloy after isothermal heat treatment at $793 \mathrm{~K}$ for $2.0 \mathrm{~min}$ are similar to those of the extruded one, which can be seen in Fig.2 and Fig.3a. With the isothermal holding time prolonging (from $2.5 \mathrm{~min}$ to 3.0 $\min$ ), the grains of primary $\alpha-\mathrm{Mg}$ undergo a growing process, which can be seen in Fig.3b and 3c. When the isothermal holding time reaches $3.5 \mathrm{~min}$, the grains continue growing and become uniform, which can be seen in Fig.3d. From Fig.3e, we can see that after isothermal heat treatment for 4.0 min, the grains grow continuously, and liquid phase appears in the triple junction of grain boundaries. From what has been mentioned above, we can come to a conclusion that during the isothermal heat treatment at semisolid temperature, the grains continue growing and then the liquid phase appears.

\subsection{Microstructure evolution of $\mathrm{Mg}-2 \mathrm{Zn}-0.5 \mathrm{Y}$ alloy after isothermal heat treatment (after liquid phase appearing)}

Fig.4 shows the microstructure evolution of $\mathrm{Mg}-2 \mathrm{Zn}-0.5 \mathrm{Y}$ alloy after the isothermal heat treatment at 813,833 and $853 \mathrm{~K}$ for 10, 20 and $30 \mathrm{~min}$. As seen from Fig.4, the microstructure of the semisolid $\mathrm{Mg}-2 \mathrm{Zn}-0.5 \mathrm{Y}$ alloy consists of liquid matrix and primary $\alpha-\mathrm{Mg}$ particles. The liquid matrix forms during 


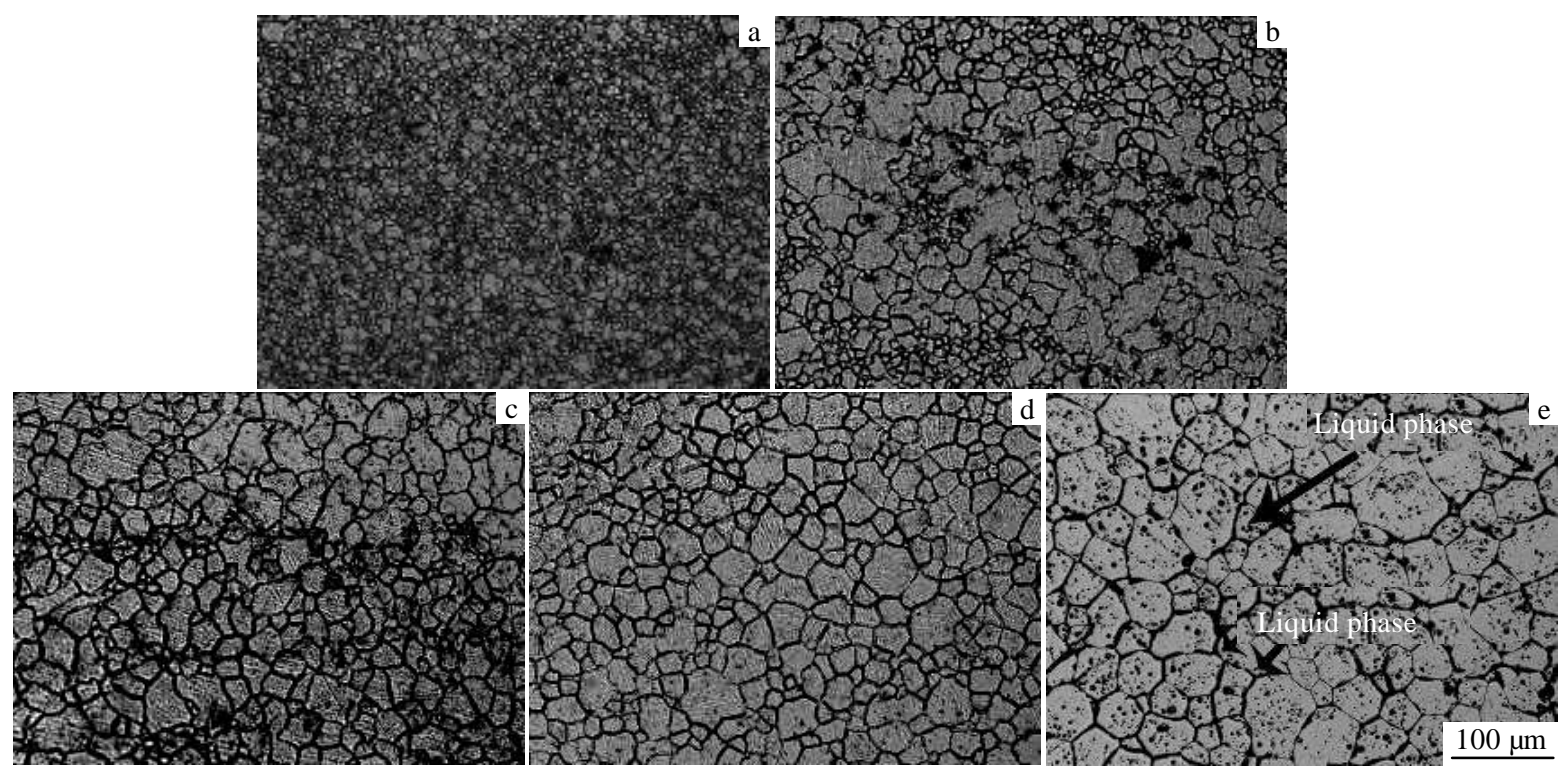

Fig.3 Microstructures of Mg-2Zn-0.5Y alloy after isothermal heat treatment at $793 \mathrm{~K}$ for different holding time: (a) $2.0 \mathrm{~min}$, (b) $2.5 \mathrm{~min}$, (c) $3.0 \mathrm{~min}$, (d) $3.5 \mathrm{~min}$, and (e) $4.0 \mathrm{~min}$
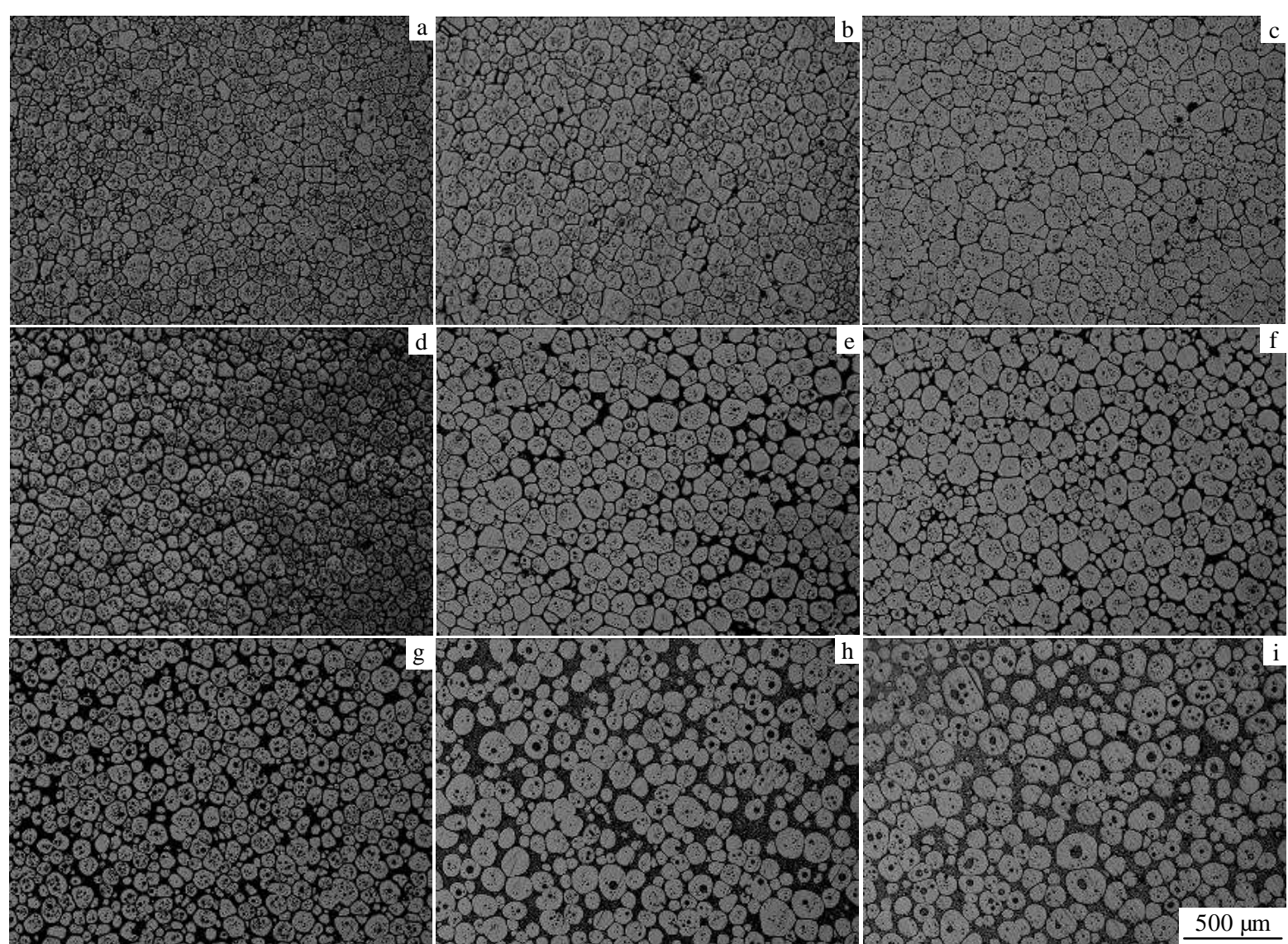

Fig.4 Microstructures of semisolid Mg-2Zn-0.5Y alloy after isothermal heat treatment at different temperatures for different time: (a) 813 $\mathrm{K} / 10 \mathrm{~min}$, (b) $813 \mathrm{~K} / 20 \mathrm{~min}$, (c) $813 \mathrm{~K} / 30 \mathrm{~min}$, (d) $833 \mathrm{~K} / 10 \mathrm{~min}$, (e) $833 \mathrm{~K} / 20 \mathrm{~min}$, (f) $833 \mathrm{~K} / 30 \mathrm{~min}$, (g) $853 \mathrm{~K} / 10 \mathrm{~min}$, (h) $853 \mathrm{~K} /$ $20 \mathrm{~min}$, and (i) $853 \mathrm{~K} / 30 \mathrm{~min}$ 
the heating and then is solidified during the quenching. Small intragranular liquid droplets can be observed, which manifests partial remelting inside of primary particles. It is obvious that liquid phase both appearing in grain boundaries and inside of particle increases significantly with the increase of isothermal temperature and prolongation of isothermal holding time.

What's more, the particle sizes increase remarkably as well. When the temperature increases to $853 \mathrm{~K}$ and the holding time is prolonged to 20 and $30 \mathrm{~min}$, we can observe that the fine droplets in the particles begin to move within the globules and combine together to form large droplets in order to decrease their surface energy, and particles begin to combine to form large particles too for the same reason, which can be seen in Fig.4h and Fig.4i.

Fig.5 shows the SEM micrograph and EDS spectra of $\mathrm{Mg}-2 \mathrm{Zn}-0.5 \mathrm{Y}$ alloys heat-treated at $853 \mathrm{~K}$ for $10 \mathrm{~min}$. As seen from Fig.5, during the isothermal heat treatment, the firstly remelt areas in the alloy are grain boundaries which have some second phases with a low melting temperature and the place $\mathrm{Zn}$ and $\mathrm{Y}$ element gathering. Then the liquid phase diffuses along the boundaries, and the primary $\alpha$-Mg particles are separated. Meanwhile, small liquid droplets appear in the particles. Moreover, from Fig.5, we can also see that the size of liquid phase along the boundaries is bigger than that of liquid droplets in the particles. That's because the grain boundaries have more $\mathrm{Zn}$ and $\mathrm{Y}$ elements compared with inside of the particles and elements diffused faster in the grain boundaries.

Fig.6 shows the quantitative result of effects of isothermal temperature and holding time on solid fraction of semisolid $\mathrm{Mg}-2 \mathrm{Zn}-0.5 \mathrm{Y}$ alloy after isothermal heat treatment. As seen from Fig.6, with the temperature of isothermal heat treatment increasing from $813 \mathrm{~K}$ to $853 \mathrm{~K}$, the liquid phase appears with a shorter isothermal holding time. In other words, high temperature shortens the time for liquid phase appearing. What's more, for the same isothermal holding time, the higher isothermal heat treatment temperature is, the lower solid fraction the alloy would have. At the same isothermal heat treatment temperature, the longer holding time is, the lower solid fraction the alloy would have.

The quantitative result of effects of isothermal temperature and holding time on average size of primary particles is illustrated in Fig.7. As shown in Fig.7, the particle size of the extruded $\mathrm{Mg}-2 \mathrm{Zn}-0.5 \mathrm{Y}$ is just $7 \mu \mathrm{m}$. However, during semisolid isothermal heat treatment, for all three isothermal temperatures, average particle sizes increase continuously, indicating continuous coarsening of primary particles. Difference of average particle size between 813 and $833 \mathrm{~K}$ is not distinct, but average particle size of $853 \mathrm{~K}$ increases obviously, showing that coarsening at $853 \mathrm{~K}$ is faster than that at 813 and $833 \mathrm{~K}$.

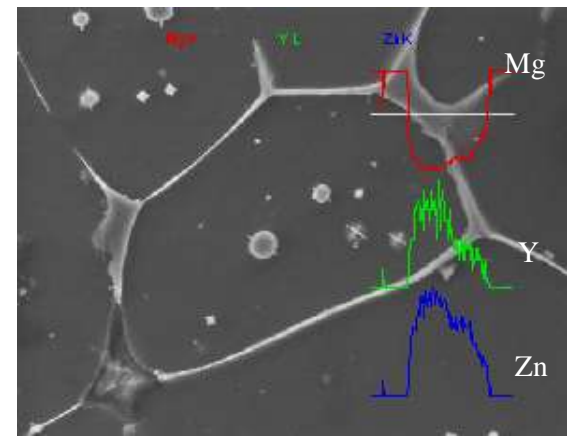

Fig.5 SEM image and EDS line scan of Mg-2Zn-0.5Y alloy heat-treated at $853 \mathrm{~K}$ for $10 \mathrm{~min}$

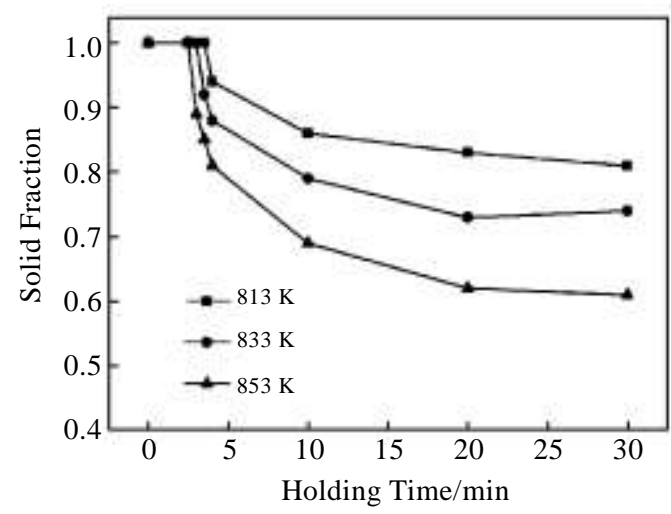

Fig.6 Effects of isothermal temperature and holding time on solid fraction of semisolid $\mathrm{Mg}-2 \mathrm{Zn}-0.5 \mathrm{Y}$ alloy after isothermal heat treatment

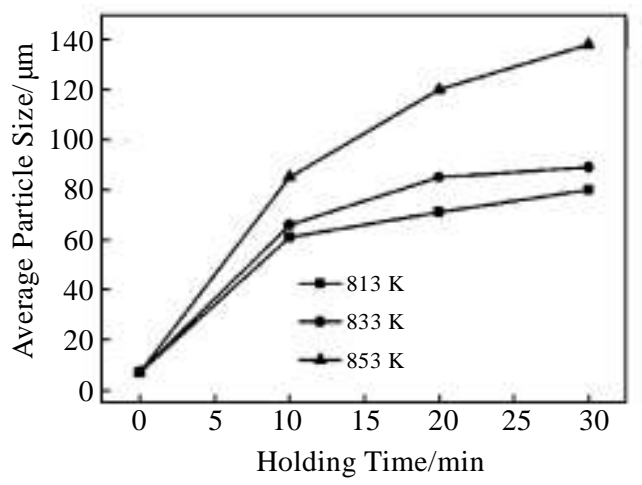

Fig.7 Effects of isothermal temperature and holding time on average primary particle size of semisolid $\mathrm{Mg}-2 \mathrm{Zn}-0.5 \mathrm{Y}$ alloy after isothermal heat treatment

Two theories are often used to explain the coarsening kinetic of primary particles in the semisolid state, i.e. particle coalescence and Ostwald ripening ${ }^{[16-20]}$. At a high solid fraction, coarsening is driven by the migration of grain boundary liquid films and the dominant mechanism for coarsening is coalescence of adjacent particles. At the same time of coarsening, particles undergo a remelting process as 
well. As a result, particle coarsening and remelting come to a state of balance. While at a low solid fraction, coarsening is driven by the dissolution of small particles and Ostwald ripening makes a major contribution to the coarsening, and coalescence of adjacent particles can still be observed, which means the coexistence of Ostwald ripening and coalescence.

The time dependency of the size of a growing particle during semisolid isothermal heat treatment can be described by a classical LSW theory ${ }^{[21]}$ :

$$
d^{n}-d_{0}^{n}=K t
$$

where, $d$ and $d_{0}$ are final and initial particle sizes respectively, $K$ is coarsening rate constant, $t$ is holding time, and $n$ is coarsening exponent. Generally, in the theory of Ostwald ripening, $n=3$ suitable for low solid fractions whose volume diffusion controls coarsening. However, the form of equation of $n=3$ is valid for most of the solid fraction range, which has been confirmed by a number of theoretical and experimental results ${ }^{[22,23]}$. Experimental results and linear regressions are shown in Fig.8. The resulted $R^{2}$ values are very close to 1 for all three isothermal temperature 813,833 and $853 \mathrm{~K}$, indicating that the experimental data are well fitted to the LSW equation at $n=3$. The coarsening rate $K$ can be obtained from the slope of the straight lines correlating the cubic $d$ and time $t$, which is $277 \mu \mathrm{m}^{3} / \mathrm{s}$ at $813 \mathrm{~K}, 406 \mu \mathrm{m}^{3} / \mathrm{s}$ at $833 \mathrm{~K}$, and 1499 $\mu^{3} / \mathrm{s}$ at $853 \mathrm{~K}$. It is obvious that the $K$ value increases with the increase of isothermal temperature from $813 \mathrm{~K}$ to $853 \mathrm{~K}$, and it is dramaticlly bigger at $853 \mathrm{~K}$ than that at 813 and $833 \mathrm{~K}$. The result proves the conclusion which has been mentioned above once again that when the isothermal temperature increases from $813 \mathrm{~K}$ to $853 \mathrm{~K}$, the dominant mechanism for coarsening changes from balance of particle coalescence and remelting to coexistence of Ostwald ripening and coalescence.

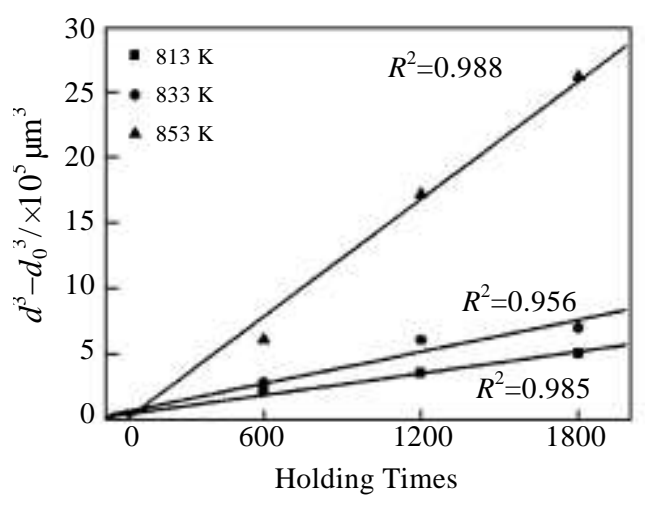

Fig.8 Effects of isothermal temperature and holding time on cube of average particle size and the results of linear regression

\section{Conclusions}

1) The microstructure of $\mathrm{Mg}-2 \mathrm{Zn}-0.5 \mathrm{Y}$ alloy consists of fine and equiaxed $\alpha-\mathrm{Mg}$ and dispersed second phase (I-Phase and W-Phase). The average grain size of primary $\alpha-\mathrm{Mg}$ is about $7 \mu \mathrm{m}$.

2) During the isothermal heat treatment at $793 \mathrm{~K}$ for 2.0 , $2.5,3.0$ and $3.5 \mathrm{~min}$, the grains continuously grow and no liquid phase appears. When the isothermal holding time reachs $4.0 \mathrm{~min}$, the liquid phase appears firstly.

3) The suitable processing parameters for the Mg-2Zn-0.5Y alloy in isothermal heat treatment are isothermal temperature of $833 \mathrm{~K}$ for $20 \mathrm{~min}$ or isothermal temperature of $853 \mathrm{~K}$ for $10 \mathrm{~min}$.

4) With the temperature of the isothermal heat treatment increasing from $813 \mathrm{~K}$ to $853 \mathrm{~K}$, the liquid phase appears with a shorter isothermal holding time. What's more, for the same isothermal holding time, the higher isothermal heat treatment temperature is, the lower solid fraction the alloy would have. At the same isothermal heat treatment temperature, the longer holding time is, the lower solid fraction the alloy would have.

5) The primary particles coarsen continuously during the isothermal heat treatment. Coarsening rate increases with the increase of isothermal temperature. When the isothermal temperature increases from $813 \mathrm{~K}$ to $853 \mathrm{~K}$, the dominant mechanism for coarsening changes from balance of particle coalescence and remelting to coexistence of Ostwald ripening and coalescence.

\section{References}

1 Zhang Q Q, Cao Z Y, Zhang Y F et al. Journal of Materials Processing Technology[J], 2007, 184: 195

2 Zhang Q Q, Cao Z Y, Liu Y B et al. Materials Science and Engineering $A[\mathrm{~J}], 2008$, 478: 195

3 Yang Guangyu, Jie Wanqi, Zhang Runqiang et al. Rare Metal Materials and Engineering[J], 2007, 36(10): 1717 (in Chinese)

4 Wang H, Davidson C J, Stjohn D H. Materials Science and Engineering $A[\mathrm{~J}], 2004$, 478: 159

5 Fan Z. International Materials Reviews[J], 2002, 47: 49

6 Liu D, Atkinson H V, Kapranos P et al. Materials Science and Engineering $A[\mathrm{~J}], 2003,361: 213$

7 Arami H, Khalifehzadeh R, Keyvan $\mathrm{H}$ et al. Journal of Alloys and Compounds[J], 2009, 468: 130

8 Koren Z, Rosenson H, Gutman E M et al. Journal of Light Metals[J], 2002, 2: 81

9 Czerwinski F. Acta Materialia[J], 2005, 53: 1973

10 Ji S, Qian M, Fan Z. Metallurgical and Materials Transactions A[J], 2006, 37: 779

11 Kleiner S, Ogris E, Beffort $\mathrm{O}$ et al. Advanced Engineering Materials[J], 2003, 5: 653

12 Lu Yizhen, Wang Qudong, Zeng Xiaoqin et al. Materials Science and Engineering A[J], 2000, 278: 66 
13 Tian X, Wang L M, Wang J L et al. Journal of Alloys and Compounds[J], 2008, 456: 412

14

Rzychon T, Kielbus A. Journal of Achievements in Materials and Manufacturing Engineering[J], 2006, 17: 83

15 Wang Y, Wang Q, Ma C et al. Materials Science and Engineering $A[\mathrm{~J}], 2003,342: 178$

16 Atkinson H V, Liu D. Materials Science and Engineering A[J], 2008, 496: 439

17 Tzimas E, Zavaliangos A. Materials Science and Engineering $A[\mathrm{~J}], 2000,289: 228$

18 Zhao Z D, Chen Q, Tang Z J et al. Journal of Materials
Science Letters[J], 2010, 45: 3419

19 Kim W J, An C W, Kim Y S et al. Scripta Materialia[J], 2002, 47: 39

20 Zhao Z D, Cheng Y S, Chen Q et al. Transactions of Nonferrous Metals Society of China[J], 2010, 20: 178

21 Luo S, Chen Q, Zhao Z. Materials Science and Engineering $A[\mathrm{~J}], 2009,506: 8$

22 Annavarapu S, Doherty R D. Acta Metallurgica et Materialia [J], 1995, 43: 3207

23 Manson-Whitton E D, Stone I C, Jones J R et al. Acta Materialia [J], 2002, 50: 2517

\title{
$M g-2 Z n-0.5 Y$ 镁合金半固态等温处理过程中的微观组织演变
}

刘 伟, 杨豆豆, 权高峰, 张英波, 姚丹丹

(西南交通大学, 四川 成都 610031)

\begin{abstract}
摘 要: 研究了挤压Mg-2Zn-0.5Y (at \%) 合金在半固态等温处理过程中的微观组织演变规律。结果表明: 挤压态的Mg-2Zn-0.5Y合金包 含 $\alpha-\mathrm{Mg}, \mathrm{Mg} 3-\mathrm{Zn} 6-\mathrm{Y} 1$ (I-Phase) 和Mg3-Zn3-Y2 (W-phase) 3种物相, 并且 $\alpha-\mathrm{Mg}$ 的平均晶粒尺寸为7 $\mu \mathrm{m} 。$ 在温度为793 K的半固态等温热处 理过程中, 晶粒不断长大, 直到保温时间达到 $4.0 \mathrm{~min}$ 时才出现液相。随着等温处理温度和时间的增加, $\alpha-\mathrm{Mg}$ 固相颗粒不断长大, 并且 逐步被液相分离; 同时, 出现在晶界的液相与颗粒内部的液滴都在不断地增多。研究还发现, 当固相率较高时, 晶粒间的合并机制与固 相颗粒再熔化机制同时起主导作用; 然而当固相率较低时, Ostwald熟化机制是主要的粗化机制, 同时也可以观察到晶粒间的合并。
\end{abstract}

关键词: $\mathrm{Mg}-\mathrm{Zn}-\mathrm{Y}$ 合金; 半固态; 等温处理; 微观组织

作者简介: 刘 伟, 男, 1988 年生, 硕士生, 西南交通大学材料科学与工程学院, 四川 成都 610031, 电话: 028-87634673, E-mail: liuwei@my.swjtu.edu.cn 